\title{
US establishes new directorate for applied research
}

IN a renewed attempt to develop an effective mechanism linking scientific research to national priorities, the National Science Foundation (NSF) announced last week that it is to set up a directorate for applied science and research applications (ASRA).

The new directorate, with an initial annual budget of about $\$ 60$ million will replace the Research Applications Directorate, which has been responsible for the increasingly-criticised programme of Research Applied to National Needs (RANN) set up in 1971 in an attempt to bridge the gap between basic research and its applications.

The main difference between RANN and the new directorate is that whereas the former was primarily organised around individual problems, ASRA has been organised on more general principles.

Thus the RANN programme has at present five separate foci, the three most important being resources, environment, and the loosely-defined field of 'advanced productivity research and applications'. In contrast, ASRA will be divided into six functionallydefined units, including an office of problem analysis, a division of integrated basic research, a division of applied research, and a division of problem-focused research applications.

In addition, whereas RANN operated relatively independently of other research programmes financed by the NSF, ASRA will work closely with the foundation's three directorates for basic science: for example it will help to identify and subsequently stimulate basic research relevant to agreed goals.

In the US, the NSF was placed on this path by a 1969 amendment to its original act under which the foundation was authorised to "support, through other appropriate organisations, applied scientific research talent relevant to national problems involving the national interest".

In line with this amendment, and with President Richard Nixon's emphasis in a State of the Union message on harnessing the "discoveries of science in the service of man", the RANN programme was set up with responsibilities that included the identification of unrecognised research needs, and increasing the effective use of science and technology in dealing with national problems.

Despite stimulating a number of important research developments-for example into the use of geothermal and solar energy-the organisational basis of RANN has in recent years encountered growing criticism, reflected in a gradual fall-off in its budget appropriation.

RANN faced the dilemma that if it defined research areas too narrowly, then many research proposals would not fit; but if the definitions were too broad, it was accused of encouraging a 'shotgun' approach to problem-solving without any clear description of research objectives.

Further criticism came from the scientific community, who objected to the apparent attempt to impose unreasonable goals on research efforts. In a highly critical report on RANN's research efforts in the applied social sciences, for example, the National Academy of Sciences claimed that these projects were "of highly variable quality and, in general, not impressive".

Although the Research Applications Directorate introduced a new structure for the RANN programme in 1976, unease remained, and in December that year a task force was set up under the chairmanship of Dr John Whinnery of the University of California, Berkeley, to 'review and advise the director on science applications across the Foundation'.

Dr Whinnery presented his report last summer, suggesting a number of alternative structures, from which the new directorate for applied science and research applications was selected by the NSF. The directorate, which comes into effect next month, is divided into six units as follows:

- The office of assistant director, which will carry out the policy-making, management, review and co-ordination functions of the directorate;

- The office of problem analysis, which will work with internal NSF and external groups and organisations in assessing problems for strategic and programmatic planning;

- The division of integrated basic research, a new section which will provide a direct link between ASRA and the basic research directorate of NSF by jointly identifying basic research related to significant national problems; - The division of applied research, whose two sections-one dealing with applied social and behavioral sciences and the other with applied physical, mathematical and biological scienceswill support research proposals benefiting social, economic and technical problems and policy issues, as well as identifying and stimulating the growth of new technologies and processes based on discoveries in various fields of science;

- The division of problem-focused research applications, which will support the application of scientific and technological capabilities to selected problems of society which are of critical national importance. (This division will initially contain four research programmes: earthquake hazard mitigation, chemical threats to man and the environment, biological alternatives for industrial feedstocks, and community water management); and

- The division of intergovernmental science and public technology, responsible for integrating science and technology into federal and state planning.

The head of the new directorate will be Dr Jack T. Sanderson, who took over the Research Applications Directorate last summer on the resignation of Dr Alfred J. Eggers, RANN's first director and now director of Lockheed's Palo Alto research laboratory.

Dr Sanderson claims that part of the new directorate has responsibility for "the most complicated part of the research spectrum" in contrast to the organisation of basic research, with its peer group system and its established paradigms. Linking research to national priorities is, he admits, an area in which the necessary mechanisms are "least well understood".

The stakes are high; no one doubts that there is a close relationship between basic research and technical development-but no one has yet come up with a totally convincing (and effective) way of pinpointing precisely how support for the former can stimulate the latter.

Will ASRA succeed where RANN seems to have failed? According to Dr Sanderson, the organisation of the new directorate is based on various models, each of which has already demonstrated a certain success, thus the integrated basic research division is modelled closely on the NSF's energy-related programme, instituted in response to the energy crisis of 1973. Under this programme NSF officials and research scientists together identified 40 priority research topics for which extra funding was subsequently made available. "Similarly the model for the problemfocused research applications division was developed after looking at the way applied research activities are carried out in government and private industry" Dr Sanderson says.

So far, the reaction to the new directorate from Capital Hill, from which some of the most vocal criticisms of 
RANN were heard, has been a cautious welcome. But President Carter is known to be carrying out assessment of the effectiveness of the current organisation of research funding. A $\$ 4$ million programme providing basic support for university research, known as "basic research stability grants", has already been "impounded" by the President from the NSF's 1978 budget prior to the outcome of this assessment.

ASRA will therefore no doubt receive close attention from both the House and the Senate during the hearings on the President's proposals for the science budget, due to take place in March.

David Dickson

\section{Shcharanskii may soon be brought to trial -without a lawyer}

THE US National Academy of Sciences has made an unprecedented demand for permission to send a legal observer to the forthcoming trial of Anatolii Shcharanskii, the Soviet cybernetician, who, until his arrest last March acted as spokesman for the unofficial 'Sunday Seminars' and was an active member of the Moscow Helsinki Monitoring Group.

Since his arrest, Shcharanskii has been held incommunicado, pending investigation on charges amounting to treason. The official 9-months investigation period expired in December, whereupon the investigating officers requested and were granted an extension of six months. Nevertheless, Shcharanskii's mother has now been told that she should find a lawyer for her son, not later than Friday, January 13, 1978 -a somewhat ironic instruction since already at least 30 Moscow lawyers have refused to act in his defence.

According to a TASS statement of 22 December, the charge against Shcharanskii is that of giving assistance to a foreign State by systematically supplying his 'masters' with slanderous information about the Soviet Union, which was then actively used for ideological diversion against the Soviet Union, and supplying to the West information about Soviet enterprises and institutions, data which constituted official secrets. Already quasijuridical 'hearings' in Stockholm, New York, Paris and London, have presented a considerable bulk of evidence in rebuttal of these charges. While the publicity value of such moves may be considerable, the comment of Literaturnaya Gazeta that it is only a court which can determine Shcharanskii's innocence or guilt and that it is not for US lawyers to maintain law and order in the USSR does have a certain justification. The move of the NAS, in requesting the presence of an observer at the trial, is possibly proving more difficult to answer, since, although the handdelivered letter was accepted by the Soviet Embassy in Washington, to date no answer has been received-a standard Soviet practice in dealing with embarrassing requests from abroad.

The NAS appeal was made by its

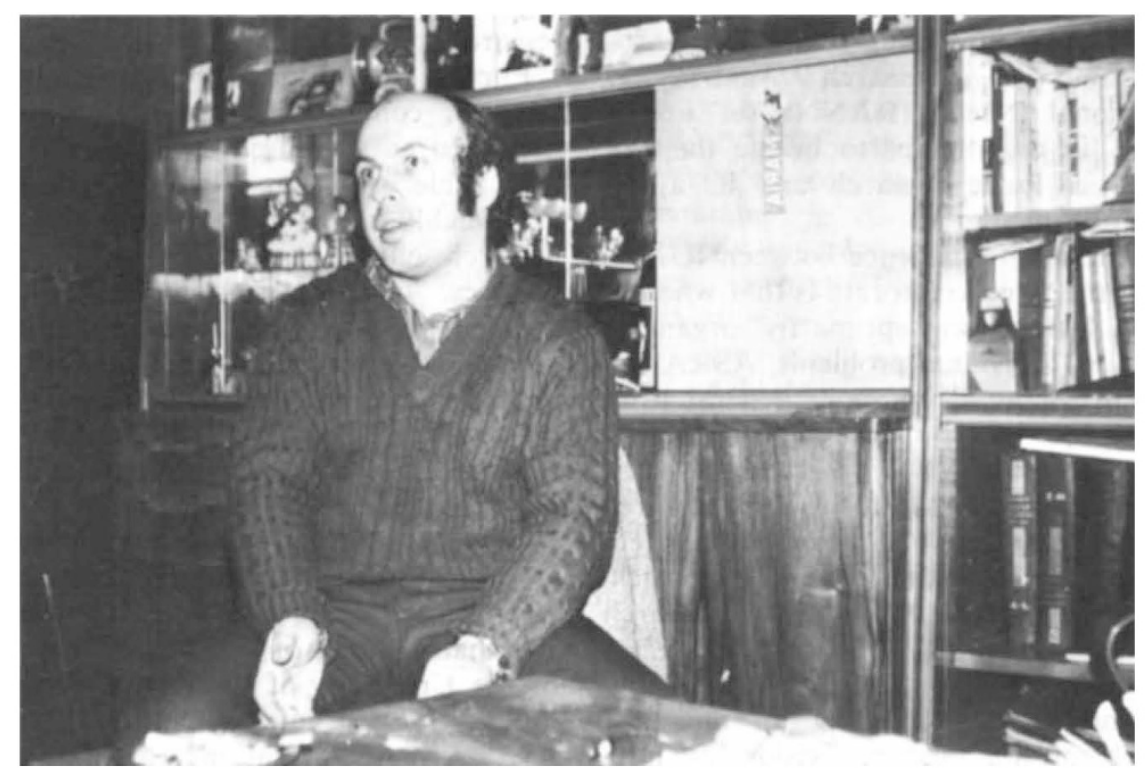

Anatolii Shcharanskii : held incommunicado

Committee on Human Rights, which was founded in 1976 at the requests of the grass-roots membership of the Academy. The Committee includes some 50 members of the Academy and in all, out of a membership of 1,200 , over 350 members have done active work on behalf of dissident or imprisoned scientists. To date, their most notable success has been the release of the Argentinian Juan Carlos Gallardo, although they freely admit that the credit for this must go not to the NAS alone but to the whole human rights movement.

The Shcharanskii appeal noted the "widespread reaction ... . and grave concern" among Shcharanskii's colleagues in the USA and elsewhere, and suggested that further action against him would "severely damage scientific interactions with the USSR". This is not an idle threat-already the American Association of Computing Machinery has threatened to break off exchange relations with the Soviet Union over the Shcharanskii case. The Human Rights Committee of the NAS acts essentially as a mouthpiece of membership pressure. If there should be a widespread demand for a severance or suspension of such agreements (and with more than a quarter of the membership actively involved in human rights activities, this is by no means impossible), the implications would be considerable. Although there exists a direct intergovernmental scientific exchange programme (established by the Nixon-Brezhnev talks of 1972), the exchange agreement between the Soviet and US Academies is a much older one (dating from 1959) and is both extensive and prestigious.

The NAS appeal is only one expression of the unprecedented concern which the Shcharanskii case has evoked. A number of factors are involved. One is, of course, the gravity of the charges. The choice of these charges, and suggestion of CIA involvement may in itself be a result of human rights action in the West. A few years ago, when intervention by such bodies as Amnesty International on behalf of dissidents became embarrassing, certain attempts were made to produce criminal charges so as to put the case outside Amnesty competence. Thus the refusnik physicist Viktor Pol'skii was accused of dangerous driving and manslaughter. The human rights activists promptly reformulated their terms of reference to include such cases, so that 